\title{
Гидродинамика слоя насыпной насадки в форме колец Мёбиуса
}

\author{
Александр Пушнов ${ }^{1}$, \\ Раиса Витковская ${ }^{2}$ \\ ${ }^{1}$ Кафедра ЮНЕСКО. Техника \\ экологччески чистых производств. \\ Московский государственныци \\ машиностроительный университет, \\ ул. Старая Басманная, д. 21/4, \\ 105066 Москва, Россия \\ Э-майл:pushnovas@gmail.com \\ ${ }^{2}$ Кафедра инженерной химии \\ и промьшленной экологии, \\ Санкт-Петербургский \\ государственный \\ университет технологии \\ и дизайна (СПбГУТД), \\ ул. Б. Морская, д. 18, \\ 191186 Санкт-Петербург, Россия
}

Представлены результаты исследования гидродинамики слоя насадки в виде колец Мёбиуса, изготовленных из различных материалов - металлической полосы, а также тканой полимерной сетки из лавсановых мононитей. Приводятся геометрические характеристики испытанных насадок, а также опытные данные по гидравлическому сопротивлению сухой и орошаемой насадки, в виде колец Мёбиуса, изготовленной из указанных материалов. Опытные данные сравниваются с наиболее распространенными промышленными насадками. Результаты исследования могут быть использованы при аппаратурном оформлении различных тепло- и массообменных процессов. Показаны перспективность насадок, выполненных в форме колец Мёбиуса, которые отличаются высоко развитой удельной поверхностью при близких значениях порозности (доли пустот) по сравнению с другими кольцевыми насадками - кольцами Палля, кольцами Рашига и кольцами ГИАП - Н3.

Ключевые слова: гидравлическое сопротивление, кольцевая насадка, удельная поверхность, порозность, эквивалентный диаметр

\section{ВВЕДЕНИЕ}

Насыпные насадки широко применяются в контактных аппаратах в химической промышленности и в теплоэнергетике для развития поверхности контакта взаимодействующих между собой газовой и жидкой фаз. При этом особого внимания заслуживают те варианты конструкции насадок, где обеспечено постоянное перераспределение потоков контактирующих фаз, а также отсутствуют застойные зоны в элементах насадки [1]. Значительный интерес в этой связи заслуживают так называемые «мини кольцевые» насадки, у которых отношение диаметра к высоте более 1 [2-5]. Ниже представлены результаты исследования гидравлического сопротивления насадки в форме колец Мёбиуса, у которых отношение максимального диаметра размера элемента к его высоте составляет для металлических колец - 3,5, а сетчатых - 6,5. Геометрическая 


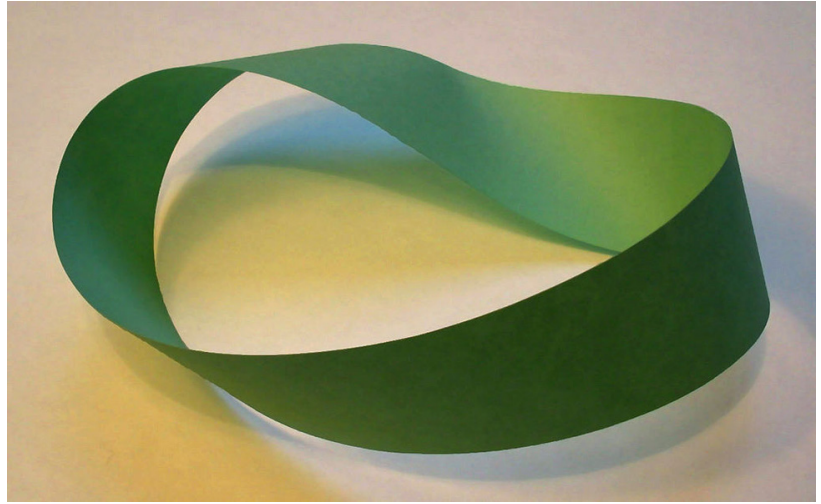

Рис. 1. Геометрическая поверхность в виде кольца Мёбиуса

фигура, известная как кольцо Мёбиуса, представляет собой тело с односторонней поверхностью (см. рис. 1). Указанная геометрическая форма создает благоприятные условия для растекания пленки жидкости по всей поверхности элемента насадки. Первые исследования насадки в форме колец Мёбиуса были опубликованы в работах [6-9].

Настоящая статья является продолжением и дальнейшим развитием указанных работ.

\section{ОПИСАНИЕ СТЕНДА И МЕТОДИКИ ЭКСПЕРИМЕНТОВ}

Испытаниям подвергали кольца Мёбиуса, изготовленные из 2-х различных материалов - из металлического листа и из тканой полимерной сетки из лавсановых мононитей. Общий вид испытанных насадок представлен на рис. 2 и рис. 3. Геометрические характеристики испытанных насадок в сравнении с другими наиболее распространенными насадками типа колец Рашига, колец Палля и колец ГИАП-НЗ близких размеров приведены в таблице.

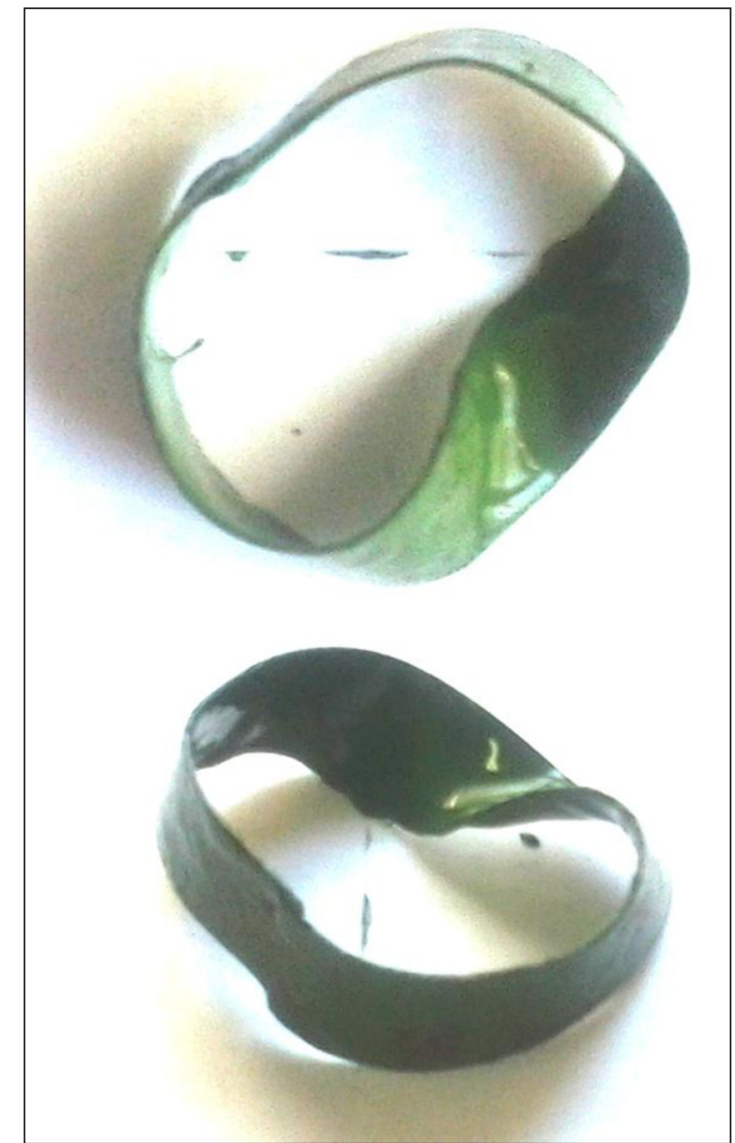

Рис. 2. Элементы насадки в форме колец Мёбиуса, изготовленных из металлической полосы

Как видно из представленных данных, геометрическая поверхность металлических колец Мёбиуса на 42 выше, чем у колец Рашига близких размеров при близких значениях порозности.

Испытания насадок проводили по стандартной методике $[7,8,11,13]$ в колонне диаметром 0,5 м. Высота слоя насадки при ее загрузке в колонну составляла в

Табл ица. Характеристики испытанных насадок в сравнении с промышленными насадками

\begin{tabular}{|c|c|c|c|c|c|c|c|}
\hline $\begin{array}{l}\text { №. } \\
\text { п/ }\end{array}$ & Тип насадки & Материал & $\begin{array}{l}\text { Поро3- } \\
\text { ность, } \\
\varepsilon, \mathrm{M}^{3} / \mathrm{M}^{3} \\
\end{array}$ & $\begin{array}{c}\text { Удельная } \\
\text { поверхность, } \\
\text { a, } \text { м²/m³ }^{3}\end{array}$ & $\begin{array}{c}\text { Эквивалентный } \\
\text { диаметр, } \\
\mathbf{d}_{\mathrm{e}^{\prime}} \text {, }\end{array}$ & $\begin{array}{c}\text { Число элемен- } \\
\text { тов в единице } \\
\text { объема N, шт }\end{array}$ & 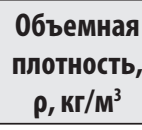 \\
\hline 1. & $\begin{array}{c}\text { Кольца Мёбиуса } \\
50 \times 15 \times 0,8 \text { мм }\end{array}$ & сталь & 0,93 & 191 & 0,01947 & 31800 & 474 \\
\hline 2. & $\begin{array}{c}\text { Кольца Мёбиуса } \\
50 \times 15 \times 0,8 \text { мм }\end{array}$ & $\begin{array}{c}\text { сетка из } \\
\text { лавсановых } \\
\text { мононитей }\end{array}$ & 0,93 & 158 & 0,0235 & 32000 & 62,4 \\
\hline 3. & $\begin{array}{c}\text { Кольца Рашига } \\
50 \times 50 \times 1 \text { мм }\end{array}$ & сталь & 0,95 & 110 & 0,035 & 7000 & 430 \\
\hline 4. & $\begin{array}{l}\text { Кольца Палля } \\
50 \times 50 \times 1 \text { мм }\end{array}$ & сталь & 0,94 & 100 & 0,0376 & 6400 & 400 \\
\hline 5. & $\begin{array}{c}\text { Кольца ГИАП-Н3 } \\
50 \times 50 \times 1 \mathrm{mм}\end{array}$ & сталь & 0,96 & 101 & 0,038 & & 400 \\
\hline 6. & $\begin{array}{c}\text { Кольца Рашига } \\
40 \times 40 \times 0,8 \text { мм }\end{array}$ & сталь & 0,93 & 140 & 0,022 & 18000 & 455 \\
\hline
\end{tabular}




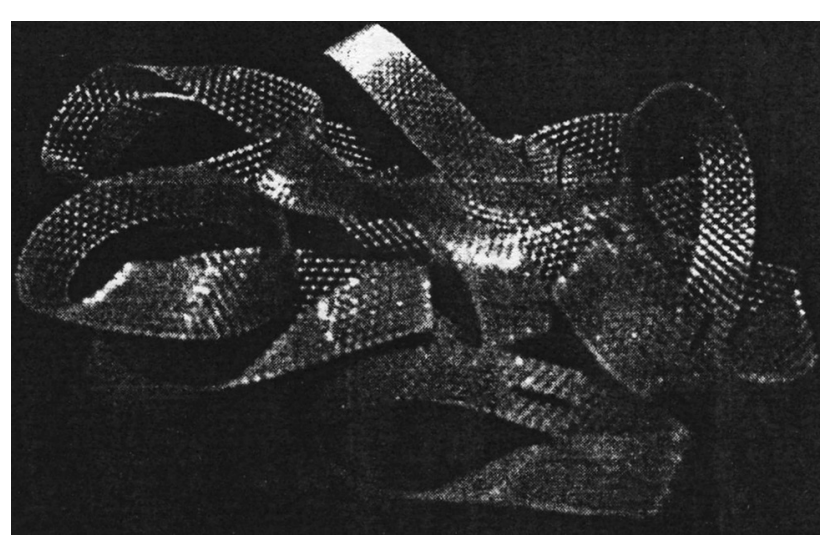

Рис. 3. Насадка в виде колец Мёбиуса, изготовленных из полимерной сетки из лавсановых мононитей

случае металлической насадки - 1,3 м, а в случае насадки из сетки - 1,0 м. Опыты проводили на системе воздух - вода при атмосферном давлении. Скорость воздушного потока в расчете на полное сечение пустого аппарата - $W_{0}$ изменяли в пределах от 0,8 до 3,4 м/с. Плотность орошения $-L_{\text {op. }}$ изменяли в пределах от 20 до $100 \mathrm{M}^{3} /\left(\mathrm{M}^{2} \cdot \mathrm{ч}\right)$.

\section{РЕЗУЛЬТАТЫ ОПЫТОВ}

Величину порозности (долю свободного объема) испытанных насадок определяли по числу элементов в единице объема, а также оценивали по количеству слитой жидкости по известной методике [1]. Разница между двумя этими значениями не превышала 2 \%. Как оказалось, полученные результаты по порозности, удельной поверхности и гидравлическому радиусу (эквивалентному диаметру канала) хорошо коррелируются с ранее установленными закономерностями [12] $d_{e}=f(a)$ для других известных типов насадок. Из приведенных в таблице 1 опытных данных видно, что значения порозности у колец Мёбиуса идентичных размеров из металла и из полимерной сетки практически совпадают. Удельная поверхность у металлических колец Мёбиуса на 17 \% выше, чем у колец Мёбиуса из сетки. При этом удельная поверхность металлических колец Мёбиуса на 37-40 \% выше по сравнению с кольцами Рашига того же размера [13] при одинаковом значении порозности.

\section{Опыты с металлическими кольцами Мёбиуса}

Результаты опытов по измерению удельного гидравлического сопротивления сухой насадки колец Мёбиуса из металлической полосы в виде графической зависимости $(\Delta P / H)=f\left(W_{0}\right)$ представлены на рис. 4. Там же показано влияние плотности орошения $-L_{\text {ор. }}$ металлической насадки на величину ее гидравлического сопротивления. Из графиков на рис. 4 видно, что результаты

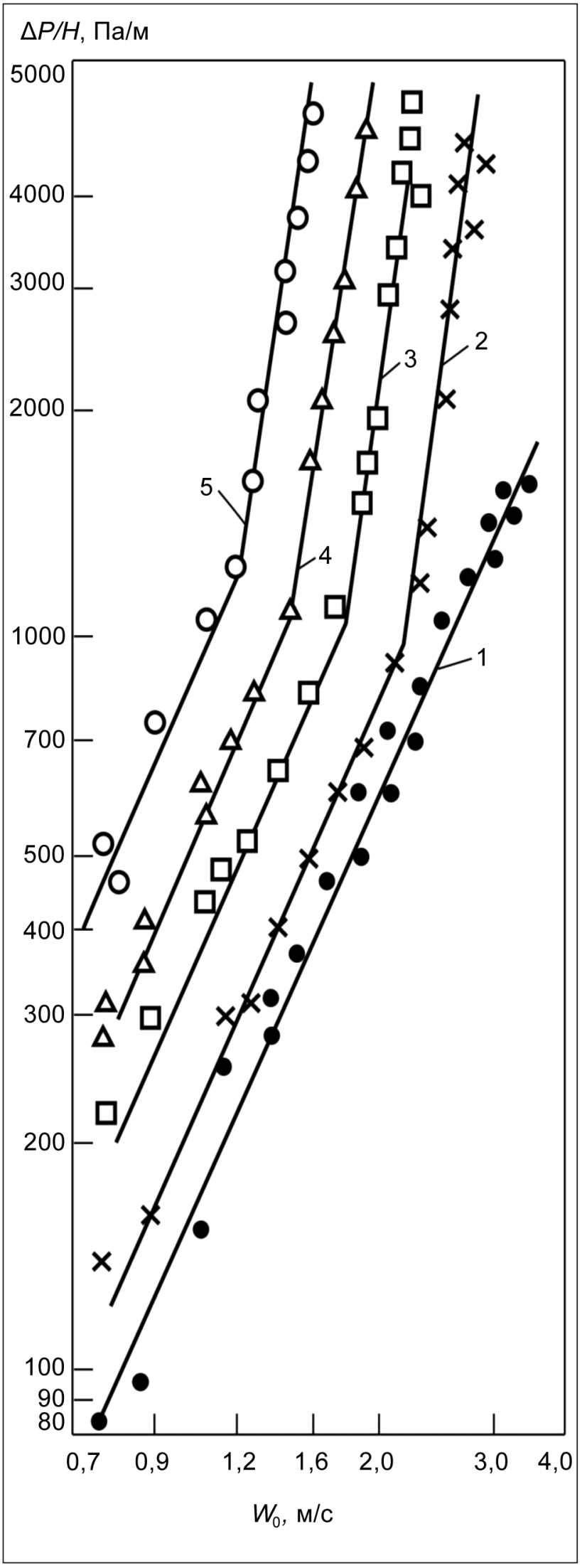

Рис. 4. Зависимость удельного гидравлического сопротивления от скорости газового потока для колец Мёбиуса из металла при различных плотностях орошения $L_{\text {ор. }}: 1-L_{\text {ор. }}=0 ; 2-L_{\text {ор. }}=20 \mathrm{~m}^{3} /\left(\mathrm{M}^{2} \cdot 4\right) ; 3-L_{\text {ор. }}=40 \mathrm{~m}^{3} /$ $\left(\mathrm{M}^{2} \cdot \mathrm{4}\right) ; 4-L_{\text {op. }}=60 \mathrm{M}^{3} /\left(\mathrm{M}^{2} \cdot \mathrm{4}\right) ; 5-L_{\text {op. }}=80 \mathrm{M}^{3} /\left(\mathrm{M}^{2} \cdot \mathrm{u}\right)$ 
измерений гидравлического сопротивления слоя сухой и орошаемой насадки в виде металлических колец Мёбиуса в зависимости от скорости газового потока в расчете на полное сечение пустого аппарата в логарифмической системе координат хорошо обобщаются прямыми линиями. Резкий излом прямых линий в случае орошаемой насадки в виде металлических колец Мёбиуса, как и у других нерегулярных насадок, объясняется переходом от пленочного режима течения жидкости к режиму подвисания [14].

\section{Опыты с насадкой из полимерной сетки}

При изготовлении сетчатой насадки использовали сетку полотняного переплетения из лавсановых мононитей. Диаметр нитей основы и утка составлял [8]: 0,65-0,8 мм. Эквивалентный диаметр отверстий в сетке составлял 0,6-0,7 мм. Живое сечение сетки - $23 \%[8,9]$.

Результаты опытов по измерению удельного гидравлического сопротивления сухих колец Мёбиуса из полимерной сетки, изготовленной из лавсановых мононитей в виде зависимости $(\Delta P / H)=f\left(W_{0}\right)$, показаны на рис. 5 в сравнении с кольцами Рашига и сёдлами Инталокс близких геометрических размеров $[8,13]$. Как это видно из графиков на рис. 5, гидравлическое сопротивление колец Мёбиуса из сетки на $220 \%$ меньше по сравнению с сёдлами Инталокс и на 280 \% меньше, чем у колец Рашига. В то же время известное [10, 11] свойство двухстороннего течения жидкости по поверхности полотна сетки, изготовленной из лавсановых мононитей, позволяет ожидать, что вся поверхность этой насадки, без образования застойных зон, будет полностью и с высокой эффективностью участвовать в процессе осуществления тепло- и массообмена.

\section{ОБСУЖДЕНИЕ}

Сравнение гидравлического сопротивления колец Мёбиуса, изготовленных из различных материалов - сетки и металла, в испытанном диапазоне скоростей, представлено на рис. 6. Можно отметить, что кольца Мёбиуса из сетки имеют до 3,5 раз меньшую величину гидравлического сопротивления, чем кольца Мёбиуса, изготовленные из металлической полосы (см. рис. 6). Сравнение насыпной насадки в виде колец Мёбиуса с наиболее распростра-

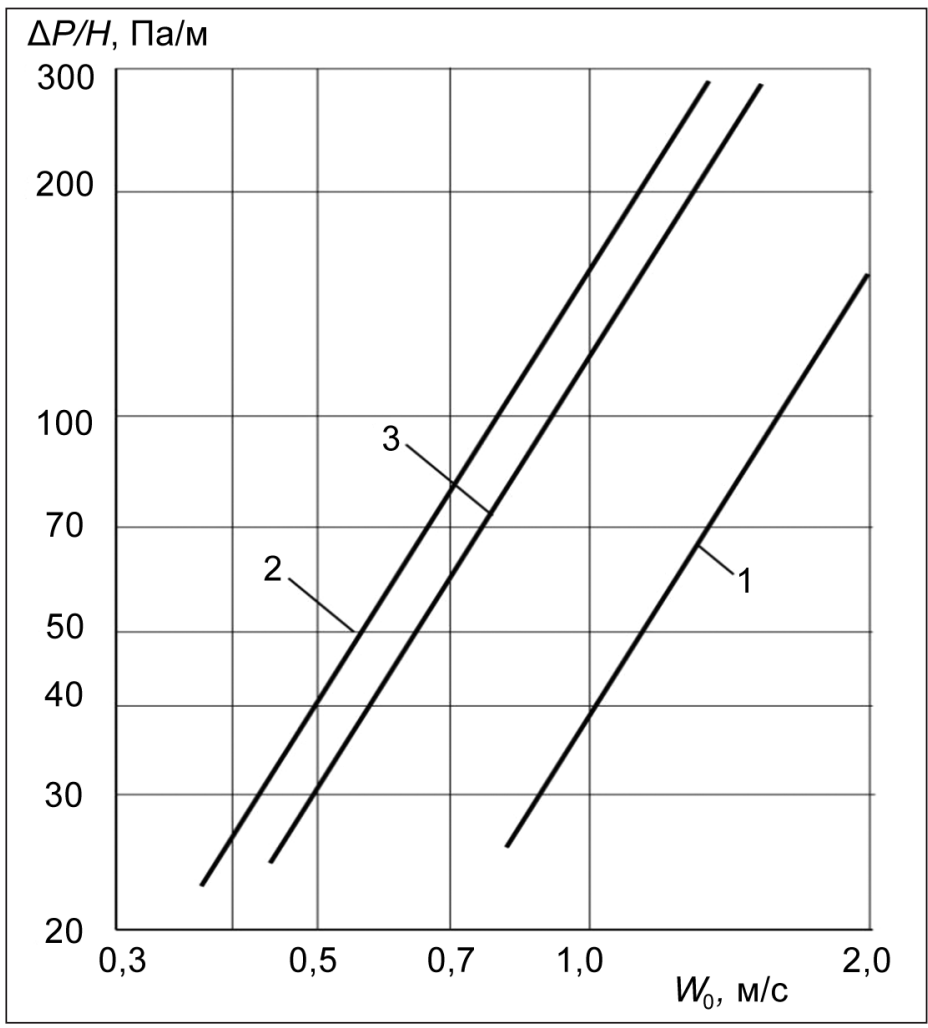

Рис. 5. Зависимость удельного гидравлического сопротивления от скорости газового потока для сухих колец Мёбиуса из полимерной сетки в сравнении с промышленными насадками: 1 - кольца Мёбиуса из сетки; 2 - кольца Рашига 50 мм; 3 - сёдла Инталокс 44 мм

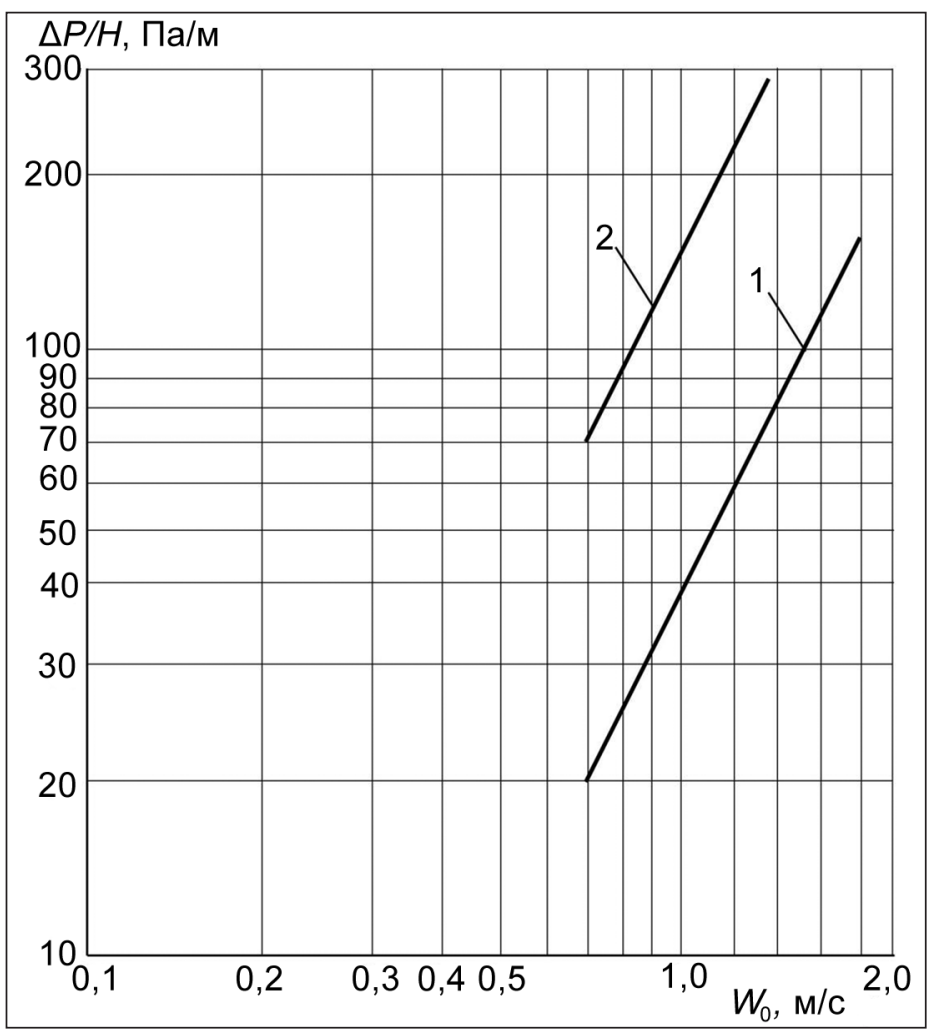

Рис. 6. Зависимость $(\Delta P / H)=f\left(W_{0}\right)$ для колец Мёбиуса: 1 - насадка из сетки; 2 - насадка из металла 
ненными промышленными насадками тех же размеров показывает, что кольца Мёбиуса имеют более высокую удельную поверхность (см. таблицу).

Геометрическая форма колец Мёбиуса является более открытой для омывания взаимодействующими потоками в системах газ - жидкость. Проведенные нами опыты с насадкой в форме колец Мёбиуса, особенно с элементами насадки из полимерной сетки, показали, что в этом случае смоченная поверхность практически равна геометрической поверхности и равна активной поверхности данной насадки. С учетом данных работы [15] это уникальное свойство колец Мёбиуса дает основания полагать, что данная насадка будет более эффективна при осуществлении процессов тепло - и массообмена по сравнению с кольцами Рашига и другими кольцевыми промышленными насадками, в которых, как известно, значительная часть поверхности не омывается жидкостью [15]. Изложенное позволяет рекомендовать кольца Мёбиуса для энергоемких технологических процессов в качестве альтернативы используемым в настоящее время кольцам Рашига, кольцам Палля и сёдлам Инталокс.

\section{ВЫВОДЫ}

1. Предлагается оригинальная конструкция насадки, выполненной в виде колец Мёбиуса, изготовленных из полимерной сетки и металла.

2. Показано, что предлагаемая насадка в виде колец Мёбиуса имеет на 37-40 \% более высокую удельную поверхность по сравнению с распространенными в промышленности насадками в виде колец Рашига.

3. Приведены геометрические характеристики и результаты исследования гидродинамики сухой и орошаемой насадки, выполненной в виде колец Мёбиуса, в диапазоне нагрузок по газу от 0,8 до 3,4 м/с и плотностей орошения от 20 до $100 \mathrm{~m}^{3} /\left(\mathrm{M}^{2} \cdot\right.$ ч).

4. Результаты исследования могут быть использованы при аппаратурном оформлении различных тепло- и массообменных процессов.

Получено 10012013 Принято 08052013

\section{Литература}

1. Пушнов А. С., Каган А. М. Структура и газораспределение в колонных аппаратах с насадкой. Колонные аппараты с насадкой для осуществления тепло- $и$ массообменных процессов. Saarbrücken: Lambert Academic Publishing, 2012. 168 c.

2. Fei W. Y. Super mini ring. Chinese patent CN 89109152.1, 1989.
3. Fei W. Y., Lanyi G. Studies on a new random packing - Plum Flower Mini Ring. Chinese Journal of Chemical Engineering. 2002. Vol. 10(6). P. 631-635.

4. Schultes M. Raschig Super-Ring: A new fourth generation packing offers new advantages. Chemical Engineering Research and Design. 2003. Vol. 81(1). P. 48-52.

5. Каган А. М., Чиж К. В., Тимонин А. С., Пушнов А. С. Сравнительные характеристики нерегулярных металлических насадок. Хим. пром-ть. 2012. Т. 89(1). С. 39-47.

6. Авторское свидетельство 631185 СССР, МКИ² BO1D 53/20. Насадка для тепломассообменных аппаратов. Гельперин И. И., Калинина С. Е., Каган А. М., Пушнов А. С., Куксо В. М., Крапивцева И. Е., Пальмов А. А. (СССР) - №. 2481322/23-26; заявл. 25.04.1977; приоритет 25.04.77; опубл. 05.11.78. Бюл. №. 41.

7. Каган А. М., Пальмов А. А., Крапивцева И. Е., Гельперин И. И. Исследование некоторых гидравлических параметров насадки в форме колец Мёбиуса. Хим. пром-ть. 1982. №. 6. С. 369-373.

8. Витковская Р. Ф. Разработка и исследование полимерных волокнистых катализаторов и контактных элементов для ресурсосбережения и охраны окружающей средь. Диссертация на соиск. уч. степени д. т. н. СПб.: СПбГУТД, 2005. 366 с.

9. Демидов А. В., Витковская Р. Ф., Терещенко Л. Я. и др. Текстиль в технике и защите окружающей среды: монография. Под ред. проф. К. Е. Перепелкина. СПб.: СПбГУТД, 2009. 338 с.

10. Пушнов А. С., Масагутов Д. М. Разработка новых конструкций регулярных насадок из полимерной сетки для осуществления процессов тепло- и массообмена. Эницклопедия инженера-химика. 2012. №. 4. C. 30-35.

11. Пушнов А. С., Каган А. М., Шинкунас С., Гимбутите И., Витковская Р. Ф., Трусов М. С., Шишов В. И. Влияние геометрии регулярной насадки из полимерной сетки на ее тепло- и массообменные характеристики. Хим. пром-ть. 2009. Т. 85(5). С. 1-14.

12. Pushnov A. Geometrical characteristics and hydraulic radius of hacking. Energetika. 2011. Vol. 57(2). P. 130133.

13. Алекперова Л. В. Разработка и исследование нерегутярных насадок применительно к процессу моноэтаноламиновой очистки газов от двуокиси углерода. Дисс. на соиск. уч. ст. к. т. н. М.: ГИАП, 1975. 251 с.

14. Balandis A., Leskauskas B., Šinkūnas S., Vaickelionis G., Valančius Z. Chemijos inžinerija. II knyga. Vadovèlis. Kaunas: Technologija, 2007. 534 p.

15. Каган А. М., Юдина Л. А., Пушнов А. С. Активная поверхность элементов нерегулярных тепло-массообменных насадок. Теоретические основы химической технологии. 2012. Т. 46. №. 2. С. 199-206. 


\section{Aleksandr Pushnov, Raisa Vitkovskaya \\ MOBIUS FORMOS ŽIEDŲ SUPILTINĖS IૃKROVOS SLUOKSNIO HIDRODINAMIKA}

\section{Santrauka}

Straipsnyje pateikti hidrodinaminiai Mobius formos žiedų supiltinès įkrovos sluoksnio tyrimai. Mobius žiedai pagaminti iš skirtingu medžiagų - metalinès juostelès bei austo lavsano polimerinio tinklo. Pateiktos eksperimentinès hidraulinio pasipriešinimo charakteristikos sausose ir drèkinamose Mobius formos žiedų įkrovose. Eksperimentiniai duomenys palyginami su labiausiai paplitusiomis pramoninèmis žiedų įkrovomis. Rezultatai gali būti panaudoti aprašant šilumos ir masès mainų procesus. Straipsnyje pateiktas Mobius žiedų ikkrovų perspektyvumas. Šių žiedų ịkrovos išsiskiria aukštu santykiniu paviršiaus plotu esant panašiam porètumui kaip ir kitose - Pall, Raschig ir GIAP-H3 - žiedų ịkrovose.

Raktažodžiai: hidraulinis pasipriešinimas, žiedinis antgalis, paviršiaus plotas, porètumas, ekvivalentinis skersmuo
Alexander Pushnov, Raisa Vitkovskaya

\section{HYDRODYNAMICS OF THE MOBIUS RING-SHAPED RANDOM PACKING}

\section{Summary}

The results of the study of fluid dynamics of bulk packing in the form of a Mobius ring, made of various materials - metal strips and plastic mesh woven by lavsan filaments, are presented. Geometry of the tested packing, as well as experimental data on the hydraulic resistance of the dry and irrigated packing are given in comparison with the most common industrial bulk packing. The results can be used for hardware design of various heat and mass transfer processes. Prospects of the accessories in the form of a Mobius ring, which have a highly developed specific surface at similar porosity (void fraction) compared with such packing as Pall, Raschig and GIAP-H3 rings, are presented.

Key words: hydraulic resistance, annulus, surface area, porosity, equivalent diameter 